\title{
Conn's syndrome due to an ectopic adrenal adenoma
}

\author{
Jayantha Arnold and Anthony Mitchell
}

Department of General Medicine, St. Ann's Hospital, London, UK.

\begin{abstract}
Summary: A 31 year old woman presented with resistant hypertension. Investigations revealed that she had Conn's syndrome. Computed tomography showed both adrenals to be normal but an ectopic adenoma was identified posterior to the stomach. Surgical excision of the tumour confirmed benign aldosteronoma and cured her hypertension. We believe this to be the first report of Conn's syndrome caused by an ectopic adrenal adenoma.
\end{abstract}

\section{Introduction}

Conn ${ }^{1}$ first described a new clinical syndrome of primary aldosteronism in 1955. Most cases of Conn's syndrome are due to solitary adrenal adenomas. ${ }^{2-4} \mathrm{We}$ report an unusual case of Conn's syndrome caused by an adrenal adenoma (aldosteronoma) found outside the left adrenal gland where both adrenals themselves were normal.

\section{Case report}

A 31 year old woman was seen in the medical outpatient clinic for difficult control of hypertension. Five years previously she was prescribed the contraceptive pill and two months later her general practitioner found the blood pressure to be raised. Blood pressure remained elevated in spite of discontinuing the contraceptive pill. She was being treated with cyclopenthiazide and atenolol at the time of presentation to the hospital. She did not complain of muscle weakness, polyuria, polydypsia, paraesthaesiae or tetany. She had not ingested liquorice preparations. There was no family history of hypertension. On examination her blood pressure was $190 / 110 \mathrm{mmHg}$. There was no radiofemoral delay of pulse. The kidneys were not enlarged and there was no renal artery bruit. The muscle power was normal. Fundi showed arteriovenous nipping.

On investigation the full blood count and blood glucose were normal. Electrocardiogram showed left ventricular hypertrophy. Chest X-ray showed cardiomegaly. Serum urea was $4.2 \mathrm{mmol} / 1$, serum creatinine $76 \mu \mathrm{mol} / \mathrm{l}$ and creatinine clearance $110 \mathrm{ml} /$ min. Her intravenous pyelogram was normal. Serum

Correspondence: J.D. Arnold, M.R.C.P., Ward B4G, University Hospital of Wales, Heath Park, Cardiff CF4 4XW, UK.

Accepted: 25 April 1989 electrolytes $(\mathrm{mmol} / \mathrm{l})$ on presentation were sodium 143 , potassium 2.2 , chloride 100 , bicarbonate 35 , and 2 weeks after stopping the diuretic the potassium level was 2.8. The 24-hour urinary excretions of electrolytes were sodium $135 \mathrm{mmol}$ and potassium $92 \mathrm{mmol}$ in a volume of $1880 \mathrm{ml}$. The 24-hour urinary-free cortisot was $126 \mathrm{nmol}$ (normal range $100-300 \mathrm{nmol}$ ). He $\vec{\Phi}$ plasma aldosterone level was $1040 \mathrm{pmol} / \mathbb{A}$ $(100-600 \mathrm{pmol} / \mathrm{l})$. Plasma renin activity in pmol pe hour per $\mathrm{ml}$ was $1.15(1.17-2.39)$ recumbent and 1.84 (2.99-4.3) ambulant. Radio-immunoassays were used to measure both plasma aldosterone ${ }^{7}$ and plasm? renin activity. ${ }^{8}$ Computed tomographic scan showed $1 \mathrm{~cm}$ diameter low attenuation cystic mass identifie $\bar{\Phi}$ above the left adrenal but both adrenals themselves were normal (Figure 1).

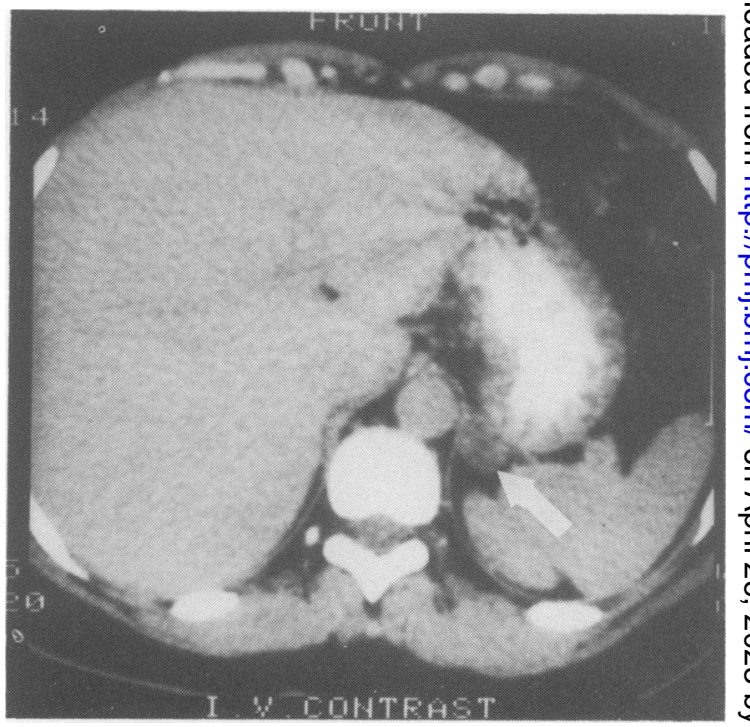

Figure 1 CT scan of abdomen demonstrating the ectopic adrenal adenoma marked by arrow.

(C) The Fellowship of Postgraduate Medicine, 1989 


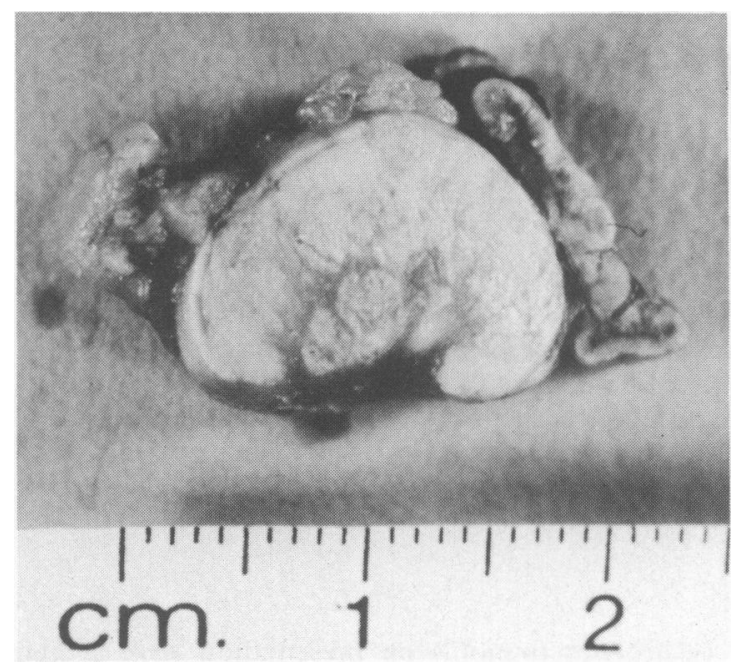

Figure 2 Macroscopic cut section of the adenoma.

She became normotensive on treatment with oral spironolactone $400 \mathrm{mg}$ daily and at surgery a $15 \mathrm{~mm} \times 7 \mathrm{~mm}$ nodule found $3 \mathrm{~cm}$ above the left

\section{References}

1. Conn, J.W. Primary aldosteronism, a new clinical syndrome. J Lab Clin Med 1955, 45: 3-17.

2. Vaughan, N.J.A., Slater, J.D.N., Lightman, S.L. et al. The diagnosis of primary hyperaldosteronism. Lancet 1981, i: $120-125$.

3. Conn, J.W., Knopt, R.F. \& Nesbit, R.M. Clinical characteristics of primary aldosteronism from an analysis of 145 cases. Am J Surg 1964, 107: 159-171.

4. Feriss, J.B., Beevers, D.G., Brown, J.J. et al. Clinical, biochemical and pathological features of low-renin ('primary') hyperaldosteronism. Am Heart J 1978, 95: 375-378.

5. White, E.A., Schambelan, M., Rose, C.R. et al. Use of computed tomography in diagnosing the cause of primary aldosteronism. N Engl J Med 1980, 303: 1503-1507. adrenal gland was excised. The cut surface of the nodule was golden yellow and the histological features were of an adrenal adenoma (Figure 2). There was no evidence of malignant change. Adrenalectomy was not required as the tumour was an ectopic one. Her blood pressure and serum electrolytes have been normal since surgery without drug therapy.

\section{Discussion}

Conn et al..$^{3}$ found muscle weakness $(75 \%)$ nocturnal polyuria (74\%), headache and polydypsia to be the four most common symptoms in their analysis of 103 patients with primary aldosteronism. Our patient did not report any symptoms at all.

Computed tomography (CT) is a valuable method of locating adrenal adenomas. ${ }^{5,6}$ Our patient had normal adrenal glands on CT scan but a small mass was noted posteromedial to the stomach above the left adrenal (Figure 1).

Normally adrenal adenomas form in the zona fasciculata of the adrenal cortex and are found within the adrenal gland. We believe this to be the first case report of Conn's syndrome caused by an aldoster onoma found outside the adrenal glands.

6. Miller, J.L., Smith, J.A. \& Mervis, B. Quantitative selenium -75- cholesterol imaging and computed tomo graphy of the adrenal glands in Conn's syndrome. $S$ Af $F$ Med J 1982, 62: 693-695.

7. Jowett, T.P. \& Slater, J.D.H. Development of radio immunoassay for measurement of aldosterone in unprocessed plasma and simple plasma extracts. Clin Chim Acta 1977, 80: 435-436.

8. Menard, J. \& Catt, K.J. Measurement of renin activity concentration and substrate in rat plasma by radioimmunoassay of angiotensin I. Endocrinology 1972, 90: 422-430. 